\title{
OPTICAL PROPERTIES OF AMORPHOUS HYDROGENATED CARBON FILMS
}

\author{
G.J. Babonas ${ }^{\mathrm{a}, \mathrm{b}}$, A. Rèza ${ }^{\mathrm{a}, \mathrm{c}}$, A. Grigonis ${ }^{\mathrm{d}}$, D. Tribandis ${ }^{\mathrm{d}}$, \\ R. Tamaševičius ${ }^{a}$, and A. Kindurys ${ }^{a}$ \\ ${ }^{a}$ Semiconductor Physics Institute, A. Goštauto 11, LT-01108 Vilnius, Lithuania \\ ${ }^{\mathrm{b}}$ Vilnius Gediminas Technical University, Saulètekio 11, LT-10223 Vilnius, Lithuania \\ ${ }^{c}$ Vilnius Pedagogical University, Studentu 39, LT-08106 Vilnius, Lithuania \\ ${ }^{\mathrm{d}}$ Kaunas University of Technology, Studentu 50, LT-51368 Kaunas, Lithuania
}

Received 22 October 2003

\begin{abstract}
Amorphous diamond-like hydrogenated carbon films grown on a Si substrate from $\mathrm{C}_{2} \mathrm{H}_{2}+\mathrm{H}_{2}$ plasma were investigated. The ellipsometric and reflectance technique was used to reveal the optical constants of a-C:H films from the optical response of the complex system in the UV-VIS-NIR spectral range of $0.5-5.0 \mathrm{eV}$. The model of an effective film was used for a-C:H films though in the analysis of the optical response a multilayer model was applied. Particular features of optical properties were correlated to the technological peculiarities and structural characteristics of a-C:H films grown from $\mathrm{C}_{2} \mathrm{H}_{2}+\mathrm{H}_{2}$ plasma.
\end{abstract}

Keywords: amorphous diamond like hydrogenated carbon films, ellipsometry

PACS: $78.66 . J g$, 81.05.Uw

\section{Introduction}

Recently, a great attention has been given to diamond-like carbon (DLC) thin films owing to their particular physical properties [1]. Optical transparency, high refractive index, chemical inertness, and high mechanical hardness are perspective characteristics for various technological applications. A lot of attempts were devoted to grow high-quality DLC films by different techniques on various substrates. For example, pulsed laser deposited [2] and sputtered [3,4] amorphous carbon films were obtained on sapphire [2,3], $\mathrm{Si}$, and glass [2,4] substrates. Sulphur-incorporated nanocrystalline carbon films were grown [5] on molybdenum by chemical vapour deposition technique. Filtered cathodic vacuum technique was used [6] for deposition of DLC films from $\mathrm{C}^{+}$ions plasma on $\mathrm{Si}$ wafers and quartz substrates. Wide investigations have shown that the physical properties and microstructure of DLC films depend significantly on the growth technology. For example, the structural changes were indicated in the studies of ion-beam-deposited amorphous hydrogenated carbon (a-C:H) films [7] at low $(100-200 \mathrm{~V})$ and high $(800 \mathrm{~V})$ acceleration potentials.
Recently, DLC thin films grown on Si substrates by plasma-enhanced chemical vapour deposition were widely studied [8-14]. The optical techniques of spectroscopic ellipsometry and Raman light scattering were frequently used for real-time in situ $[12,15]$ and $e x$ situ characterization of DLC films. On the basis of recent studies, the main regularities in the structure and properties of DLC films were revealed $[16,17]$. DLC was defined [17] as a metastable form of amorphous carbon $(\mathrm{a}-\mathrm{C})$ containing a significant fraction of metastable $s p^{3}$ bonding as well as threefold coordinated stable $s p^{2}$ carbon sites with a small fraction of $s p^{1}$ sites and some hydrogen in hydrogenated (a-C:H) samples. From this point of view, the series of DLC is considered [18] with increasing $s p^{3}$ content starting from glassy and graphitic carbon, to a-C:H, hydrogenfree tetrahedral amorphous carbon (ta-C) or ta-C:H. In DLC the $s p^{3}$ content was shown to increase linearly with density [17]. The changes in atomic structure were determined by optical spectroscopy $[16,17]$, electron energy loss spectroscopy [19], and phonon spectra $[4,5,11-13,15]$. The $\pi$-states of $s p^{2}$ sites form the localized bands within the $\sigma-\sigma^{*}$ bandgap originated from $s p^{2}$ and $s p^{3}$ sites. As a result, the shift of Tauclike absorption edge from $0.5 \mathrm{eV}$ [20] to $4 \mathrm{eV}$ [17] indicated an increase of the $s p^{3}$ fraction. The fine structure 
of Raman spectra gives information on the arrangement of $s p^{2}$ sites. The G-mode (at $\sim 1500 \mathrm{~cm}^{-1}$ ) is due to the bond stretching vibrations of the $s p^{2}$ sites pairs whereas the D-mode (at $\sim 1300 \mathrm{~cm}^{-1}$ ) is originated from the breathing mode of sixfold $s p^{2}$ rings [21]. The information about the configuration of $s p^{2}$ sites and $s p^{3}$ fraction is derived from the energy, area, and width of Raman peaks. An additional Raman peak at $\sim 1050 \mathrm{~cm}^{-1}$ is directly related to the $s p^{3}$ bonding [11]. Thus, the optical studies provide an effective method for investigation of the electronic structure as well as for characterization of the microstructure $[5,14]$ of DLC films.

The studies of hydrocarbon films deposited by plasma chemical vapour deposition have shown [8] the influence of hydrocarbon source gas on the film properties. In this work the DLC films, which have been grown on $\mathrm{Si}$ substrates from the plasma of mixture of unsaturated hydrocarbon $\mathrm{C}_{2} \mathrm{H}_{2}$ with hydrogen, were investigated by optical, mainly ellipsometric, techniques. The main goal was to reveal the correlation between the growth regimes and characteristic features of the optical response.

\section{Experimental}

The series of the DLC samples (Table 1) were grown on $p$-Si:B (111) substrates $(10 \Omega \cdot \mathrm{cm})$ from the plasma of acetylene $\mathrm{C}_{2} \mathrm{H}_{2}$ and hydrogen mixture at $1.08 \mathrm{keV}$ and $0.12 \mathrm{~mA} / \mathrm{cm}^{2}$. The substrate surfaces were variously treated before the deposition procedure. Details of the growth technology and the structure of DLC films are described in [22,23].

Spectroscopic ellipsometry measurements were carried out at room temperature in the range of $0.5-5.0 \mathrm{eV}$ by means of a computer-controlled photometric ellipsometer with a rotating analyser. The optical response of the investigated system was characterized by complex reflectance

$$
\rho=\frac{R_{\mathrm{p}}}{R_{\mathrm{S}}}=\tan \Psi \exp (\mathrm{i} \Delta),
$$

where $R_{\mathrm{p}}$ and $R_{\mathrm{s}}$ are Fresnel reflection coefficients for light polarized parallel $(\mathrm{p})$ and perpendicular $(\mathrm{s})$ to the plane of light incidence and $\Psi, \Delta$ are ellipsometric parameters. From the measurement data the ellipsometric parameters $\Psi$ and $\Delta$ were calculated making use of regression analysis and excluding systematic errors due to photocathode nonhomogeneity and nonlinearity of the photodetector and electronic amplifying devices [24].
Table 1. Growth conditions for the investigated DLC samples: growth time $t_{\mathrm{G}}$, ratio $r$ of $\mathrm{C}_{2} \mathrm{H}_{2}$ and $\mathrm{H}_{2}$ amount, time $t_{\mathrm{T}}$ of treatment in $\mathrm{H}_{2}$ plasma.

\begin{tabular}{cccc}
\hline Sample & $t_{\mathrm{G}}(\min )$ & $r\left(\mathrm{C}_{2} \mathrm{H}_{2}: \mathrm{H}_{2}\right)$ & $t_{\mathrm{T}}(\min )$ \\
\hline $\mathrm{B} 1 \mathrm{P} 4$ & 30 & $1: 0$ & 4 \\
$\mathrm{~B} 1 \mathrm{P} 1$ & 30 & $1: 1$ & - \\
$\mathrm{B} 2 \mathrm{P} 1$ & 30 & $1: 1$ & 10 \\
$\mathrm{~B} 3 \mathrm{P} 3$ & 90 & $1: 1$ & 10 \\
$\mathrm{~B} 1 \mathrm{P} 3$ & 30 & $1: 2$ & 2 \\
\hline
\end{tabular}

The experimental data were analysed in the models of effective layers and a multilayer system [25]. In the latter case the Maxwell equations were solved [26] using the transfer matrix technique [27] for both the direct and inverse problem.

The null-ellipsometer LEM-3M operating with a $\mathrm{He}-\mathrm{Ne}$ laser $(633 \mathrm{~nm})$ was also used in the measurements of $\Psi, \Delta$ dependence on the angle of light incidence. The standard reflectance measurements were made by means of a dual-beam spectrophotometer SPECORD UV-VIS supplied with a reflectance unit operating at an angle of incidence equal to $22^{\circ}$. In the near-IR the reflectance was determined at an angle of incidence equal to $6^{\circ}$ using a set-up based on a monochromator SPM-2 with a Si photodiode and a PbS resistor as detectors.

The morphology of DLC a-C:H/Si samples was studied by AFM Explorer.

\section{Results and discussion}

The quality of investigated DLC samples is illustrated by AFM images (Fig. 1). The DLC films possess some large $(20-50 \mu \mathrm{m})$ growth defects (Fig. 1(a)), in the region of which DLC was not formed. The crosssection at these defects was used for the estimation of the DLC film thickness. In the samples which have been treated by $\mathrm{H}_{2}$ plasma before the growth procedure the other-type defects along the dislocation lines are revealed (Fig. 1(b)). These defects are of the height $\sim 50 \mathrm{~nm}$ and width $\sim 500 \mathrm{~nm}$. In addition, larger defects of the width $\sim 5 \mu \mathrm{m}$ and the height up to $250 \mathrm{~nm}$ were noticed. On the other hand, in smooth parts of the surface a root mean square surface roughness is about $1.0 \mathrm{~nm}$ over an area of $1 \times 1 \mu \mathrm{m}^{2}$.

Figure 2 shows the reflectance spectra of investigated DLC films. The spectra contain the interference pattern, which was used for an estimation of the optical thickness $n d$ in the model of a uniform homogeneous layer (Fig. 3): $2 n d=m \lambda / 2$, where $n$ is refractive index, $d$ is thickness of the layer, and $\lambda$ is the position 


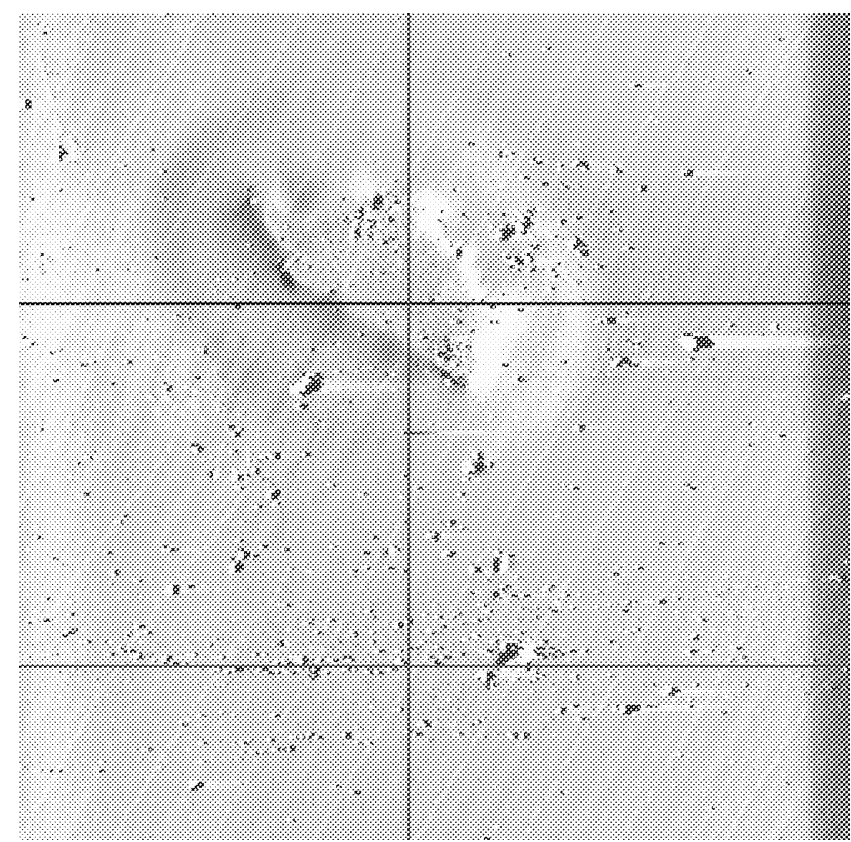

(a)

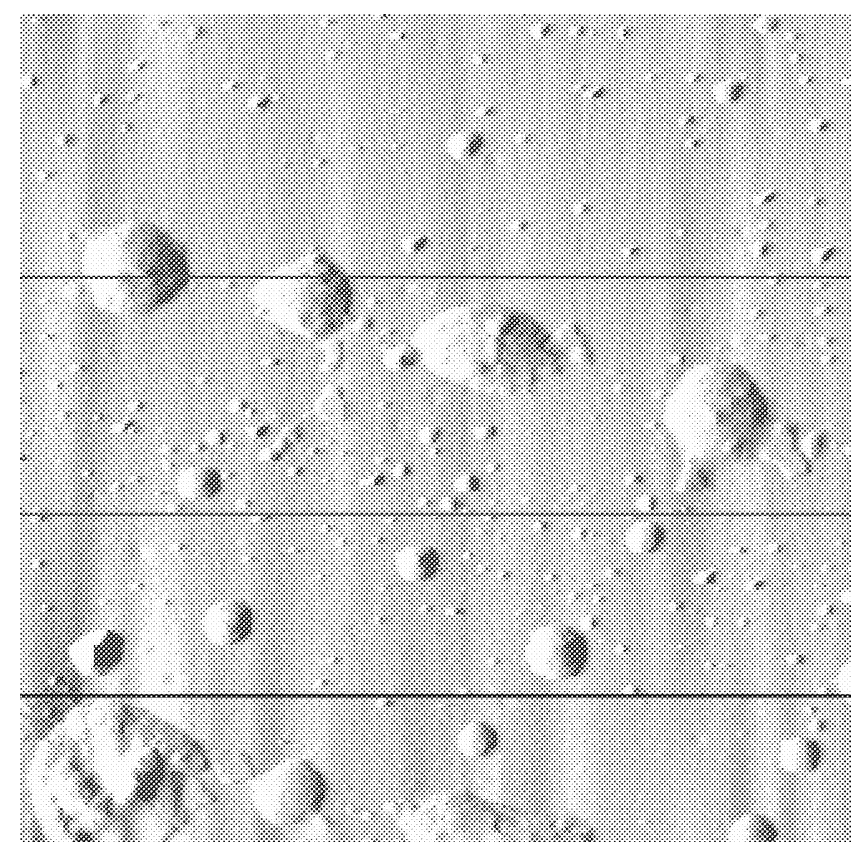

(b)

Fig. 1. AFM images of DLC films (a) B1P1N (area $100 \times 100 \mu \mathrm{m}^{2}$ ) and (b) B3P3 $\left(5 \times 5 \mu \mathrm{m}^{2}\right)$.

of interference extrema of the order $m$. The reflectance spectra of thin samples (Fig. 2(a)) were strongly influenced by the interface substrate-DLC film in the UV region and by the back-side reflection of the substrate in the IR region starting from $\sim 1 \mu \mathrm{m}$, at the indirect absorption edge of Si. As follows from comparison of Figs. 2(a) and (b), in the reflectance spectra of thicker DLC films the value of the reflection coefficient at the

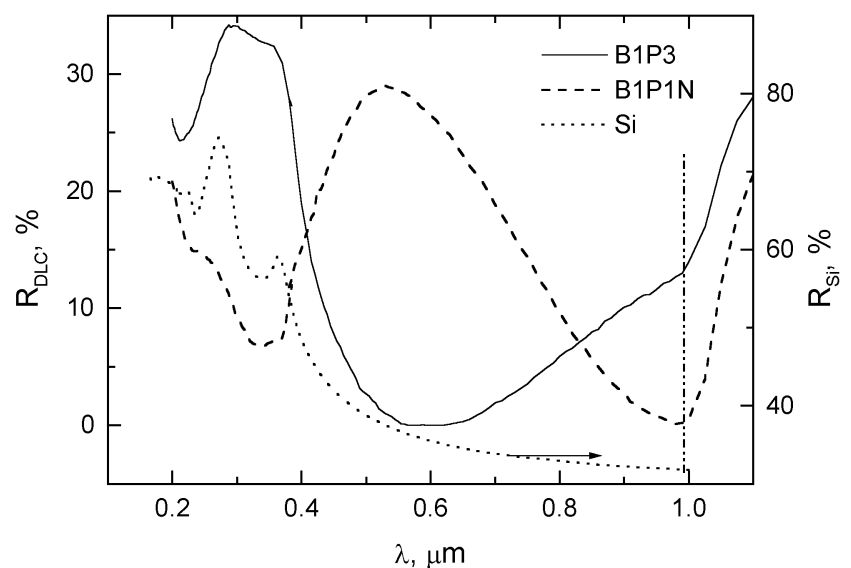

(a)

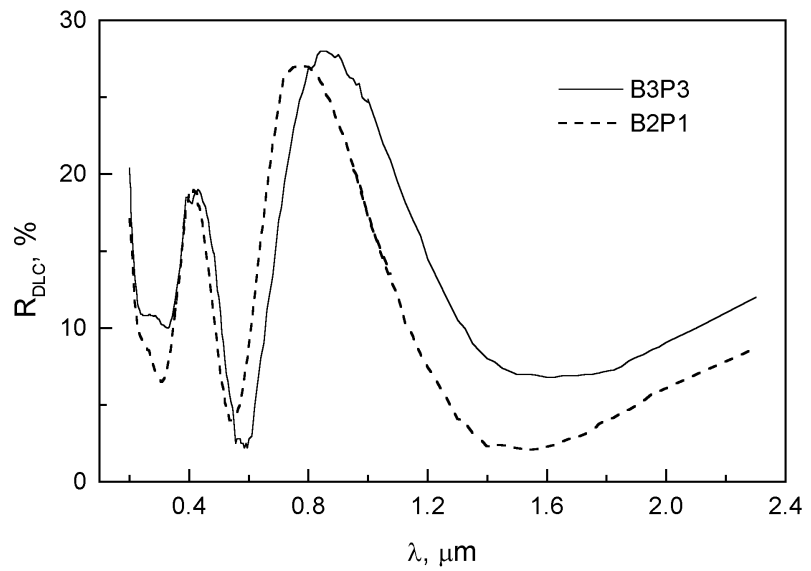

(b)

Fig. 2. Reflectance of (a) thin and (b) thicker films of DLC on Si. In (a) reflectance of $\mathrm{Si}$ is shown for comparison and the vertical line indicates the reflectance from the back side of substrate.

interference minimum $m=1$ increased due to the possible structural changes at the DLC-substrate interface.

The data presented in Fig. 3 illustrate that the dispersion of refractive index is not large. An increase of dispersion at short wavelengths is most probably due to the influence of the substrate and possible absorption of DLC film. More precise data in the region of relative transparence were obtained from the studies carried out by null-ellipsometry technique at $633 \mathrm{~nm}$ (Fig. 4). The model of the effective homogeneous layer fits experimental results with an accuracy of $1.5-3 \%$. The reference data for Si were taken from [28].

Numerical values of optical parameters for DLC films obtained from reflectance and null-ellipsometry measurements are summarized in Table 2. Accepting the film thickness values estimated from nullellipsometry, the refractive indices determined from reflectance spectra were calculated. As seen from Ta- 


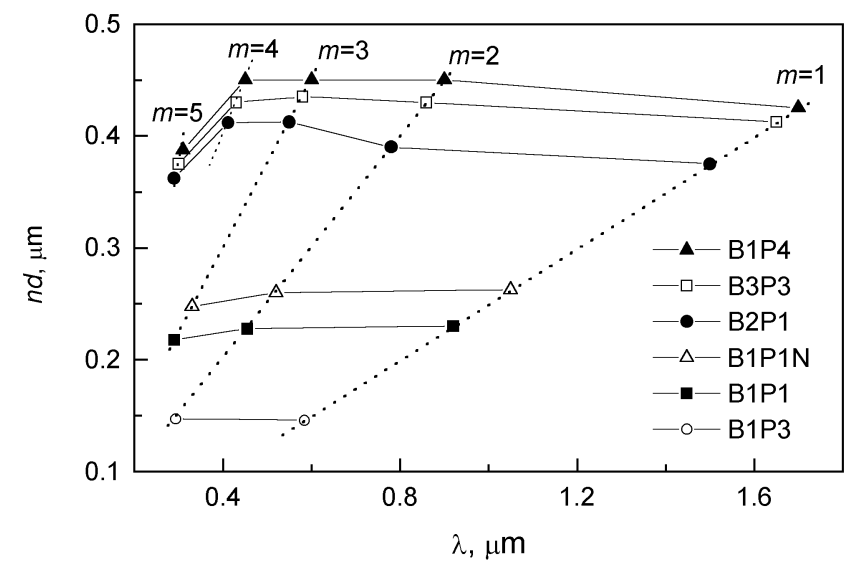

Fig. 3. The spectral dependence of optical thickness for investigated DLC films interpreted in the model of a homogeneous effective layer.

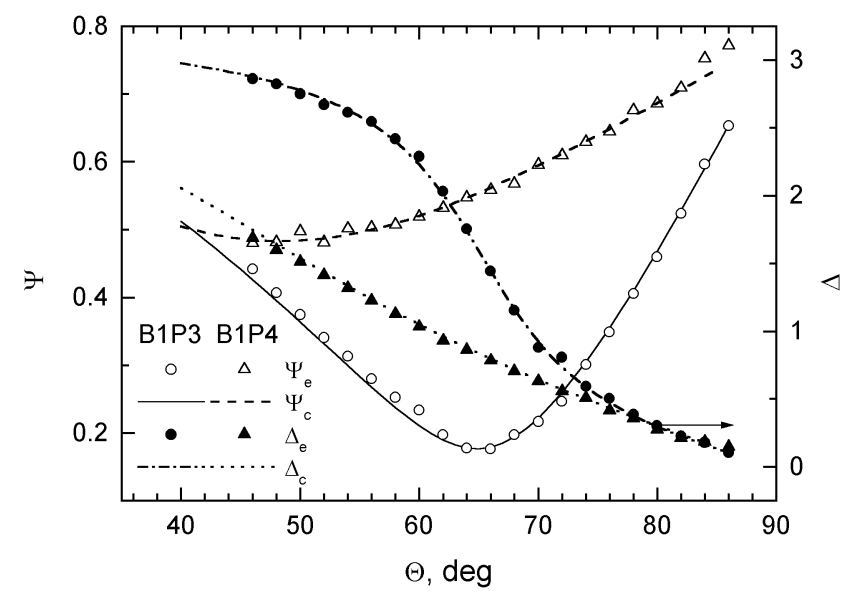

Fig. 4. The dependence of ellipsometric parameters $\Psi$ and $\Delta$ on the angle of light incidence $\Theta$ determined by null-ellipsometry at $633 \mathrm{~nm}$.

Table 2. Characteristics of the samples from reflectance and nullellipsometry measurements.

\begin{tabular}{lccccc}
\hline \multirow{2}{*}{ Sample } & \multicolumn{2}{c}{ Reflectance } & & \multicolumn{2}{c}{ Null-ellipsometry $(633 \mathrm{~nm})$} \\
\cline { 2 - 3 } \cline { 5 - 5 } & $n d(\mu \mathrm{m})$ & $n$ & & $n$ & $d(\mathrm{~nm})$ \\
\hline B1P3 & 0.15 & 2.1 & 2.06 & 71 \\
B1P1 & 0.23 & 2.3 & & 2.28 & 96 \\
B1P1N & 0.25 & 2.5 & 2.41 & 99 \\
B2P1 & 0.38 & 2.5 & & 2.80 & 150 \\
B3P3 & 0.42 & 2.3 & 2.42 & 184 \\
B1P4 & 0.45 & 2.7 & 2.72 & 169 \\
\hline
\end{tabular}

ble 2, the data obtained by different techniques are in a reasonable agreement. The film thickness obtained from ellipsometry corresponds to that determined by AFM. It should be noted that B1P1 and B1P1N are actually the same sample and the corresponding data illustrate the nonhomogeneity of the DLC film over the surface. The variation in the thickness $d$ and the refractive index $n$ is about $10 \mathrm{~nm}$ and 0.1 , respectively.

As follows from Table 2, with respect to the $n$ values, the samples can be divided into three groups. The highest values $(n \sim 2.75)$ were observed for samples $\mathrm{B} 2 \mathrm{P} 1$ and B1P4. The values $n \sim 2.35$ were determined for samples B1P1 and B3P3. The lowest value $(n=2.06)$ was found in the thinnest sample B1P3. The results indicate that the refractive index shows a tendency to increase with increasing thickness. In addition, a large difference in refractive index of a-C:H films in samples B1P4 $(n=2.72)$ and B1P3 can be interpreted by the influence of $\mathrm{H} /(\mathrm{H}+\mathrm{C})$ content during the growth procedure in a qualitative agreement with the corresponding correlation determined in [29].

It should be noticed that the interaction of $\mathrm{H}_{2}$ plasma with hydrocarbon $\mathrm{C}: \mathrm{H}$ films influences significantly the optical properties [30]. The interaction of $\mathrm{H}_{2}$ plasma with hard carbon films without additional biasing during the growth procedure leads to transformation of $s p^{2}$ sites into $s p^{3}$. On the contrary, the interaction of $\mathrm{H}_{2}$ plasma with a polymeric film at additional biasing results in transformation of $s p^{3}$ sites to $s p^{2}$.

As a whole, in the series of samples B1P3-B1P1$\mathrm{B} 1 \mathrm{P} 4$ the $d$ (as well as $n d$ ) values of investigated a-C: $\mathrm{H}$ films scale linearly with respect to the $\mathrm{C}_{2} \mathrm{H}_{2}$ amount in the plasma. The $\mathrm{H}_{2}$ plasma etched surface of samples B1P4 and B1P3 favours the growth of DLC films. In addition, the presence of the natural oxide $\mathrm{SiO}_{2}$ film on the non-etched surface of sample B1P1 can act as a catalytic agent in the DLC film growth procedure. On the other hand, a long growth time in the procedure of sample B3P3 can lead to the changes in the structure and composition of the interface and result in the optical properties different from the other samples of the investigated series.

Making use of the transfer matrix technique, the reflectance spectra for the system a-C:H/Si was calculated. A qualitative agreement between the calculated and experimental data was found. However, the model of an effective homogeneous DLC film on a crystalline Si substrate should be specified in order to achieve better correspondence.

The next step in understanding the optical properties of a-C:H/Si was made on the basis of spectroscopic ellipsometry studies. Figure 5 illustrates the experimental results for (a) thin and (b) thick samples. The measured spectra of ellipsometric parameters were fitted by calculated curves in some models. In the case of thin samples (see Table 2) the optical response of a-C:H/Si was modelled using the reference data for "amorphous 


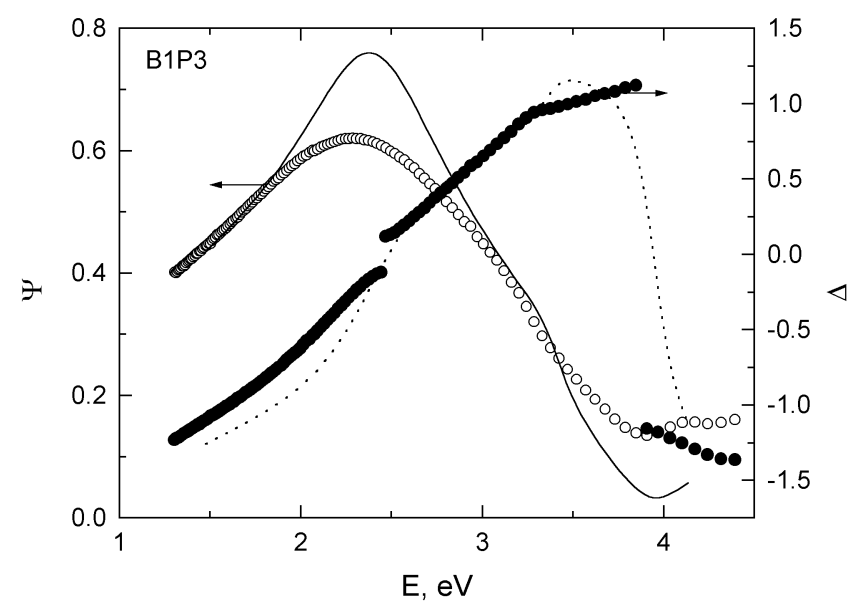

(a)

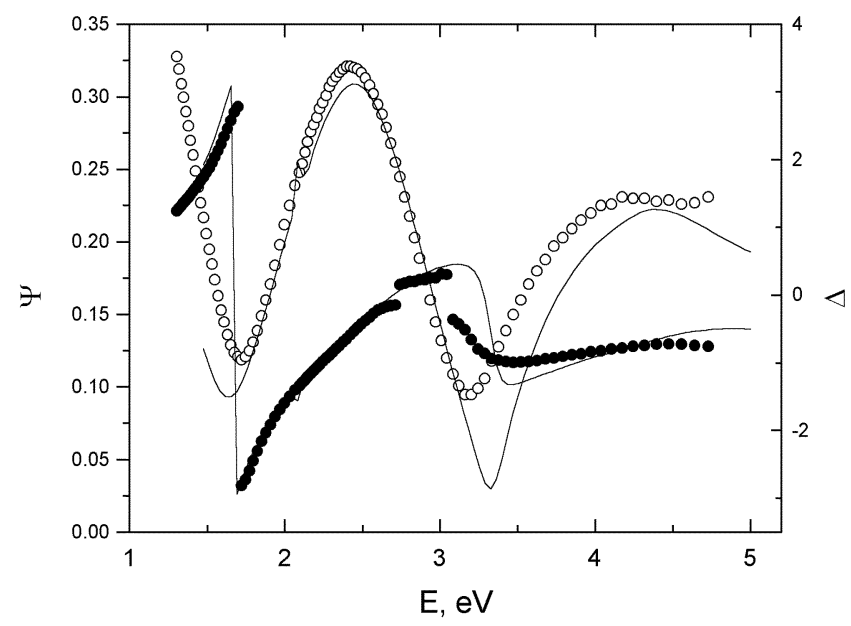

(b)

Fig. 5. Experimental (points ) and calculated (curves) spectra of ellipsometric parameters for samples (a) B1P3 and (b) B2P1 from the groups of thin and thicker DLC films, respectively.

carbon" [28] which most probably represented averaged characteristics of DLC. Accepting the value for the thickness of the a-C:H film from Table 2, a reasonable agreement between the calculated and experimental data was noticed.

In the case of thick samples, the relative intrinsic contribution of the DLC film to the total optical response of the a-C:H/Si system was high enough to specify the structure of the sample more precisely. As a rule, the optical response of the a-C:H/Si system is modelled by a multilayer structure $[10,14,29]$. A graded layer can model the substrate-DLC interface [29]. However, as noticed above analysing reflectance data, the surface of the Si substrate in the investigated samples is damaged upon the treatment by $\mathrm{H}_{2}$ plasma. It is reasonable to assume that the effect of substrate surface roughness can be taken into account by inclusion of a thin layer of porous $\mathrm{Si}$ (por-Si) [31]. In addi- tion, the observation of the a-C:H/Si samples under an optical microscope allows one to predict that a thin $\mathrm{SiC}$ layer is formed at the substrate-DLC interface. The presence of the $\mathrm{SiC}$ layer is highly probable in the technological procedure used. Thus, the optical response of the a-C:H/Si system was modelled by a multilayer structure $\mathrm{DLC} / \mathrm{SiC} /$ por-Si/Si.

Various models were used for a presentation of the spectral dependence of the dielectric function for DLC. The formulas [32] for a smooth absorption edge of amorphous semiconductors were applied for dispersion of ta-C [29], sulphur incorporated nanocrystalline carbon [5]. On the other hand, Lorentzian-like terms or their modifications were used for fluorinated nanocarbon films [11] and other DLC layers [13]. The Lorentzian line approximation

$$
\varepsilon(E)=\varepsilon_{\infty}+\sum_{k} \frac{A_{k}}{E_{k}^{2}-E^{2}-\mathrm{i} E \Gamma_{k}},
$$

where $\varepsilon_{\infty}$ is the high-energy dielectric constant, $A_{k}$, $E_{k}$, and $\Gamma_{k}$ are the amplitude, the energy, and the halfwidth of the $k$ th line, is particularly convenient for optical data analysis below the absorption threshold.

We have chosen two or three Lorentzian-like terms with adjustable parameters $A_{k}, E_{k}$, and $\Gamma_{k}$ in the fitting procedure of the experimental spectra for ellipsometric parameters (Fig. 5(b)). The dielectric function spectra of DLC are presented in Fig. 6 together with the reference data. As seen, the dielectric function for samples B2P1 and B1P4 is close to that for metastable a-C film with a high percentage (76\%) of diamond like component according to the estimation made in [33]. The lower values of absorption in these samples as compared to glassy carbon [15] confirm a large amount of $s p^{3}$ bonds. As it is widely recognized [9], the energy of the $\sigma \rightarrow \sigma^{*}$ transitions in the $s p^{3}$ sites is higher than for the $\pi \rightarrow \pi^{*}$ excitations in $s p^{2}$ sites. As seen from Fig. 6(b), the energy of the maximum absorption in a-C [28] $(\sim 3.5 \mathrm{eV})$, which has been accepted to be characteristic of the thin DLC films investigated, corresponds to that for $s p^{2}$-bonded carbon in diamond films [15]. Thus, it is reasonable to assume that the amount of the $s p^{2}$ sites is higher in the investigated thin a-C:H films (samples B1P3, B1P1).

The dielectric function for a-C:H/Si sample B3P3 differs significantly from those of the other thick DLC films. A lower absorption value in the energy region $1-3.5 \mathrm{eV}$ indicates a higher content of $s p^{3}$ bonded sites. A steeper slope of the absorption edge can be due to formation of a better-defined Tauc-like gap [29]. 


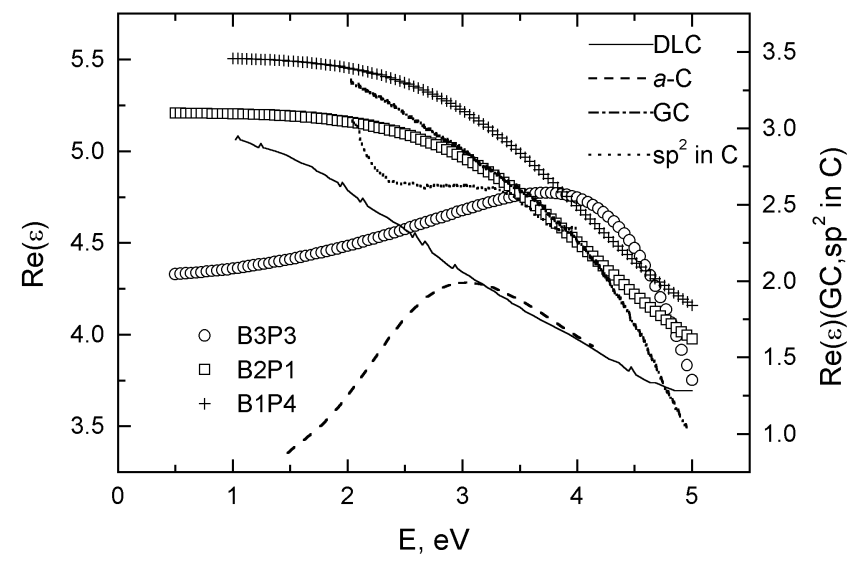

(a)

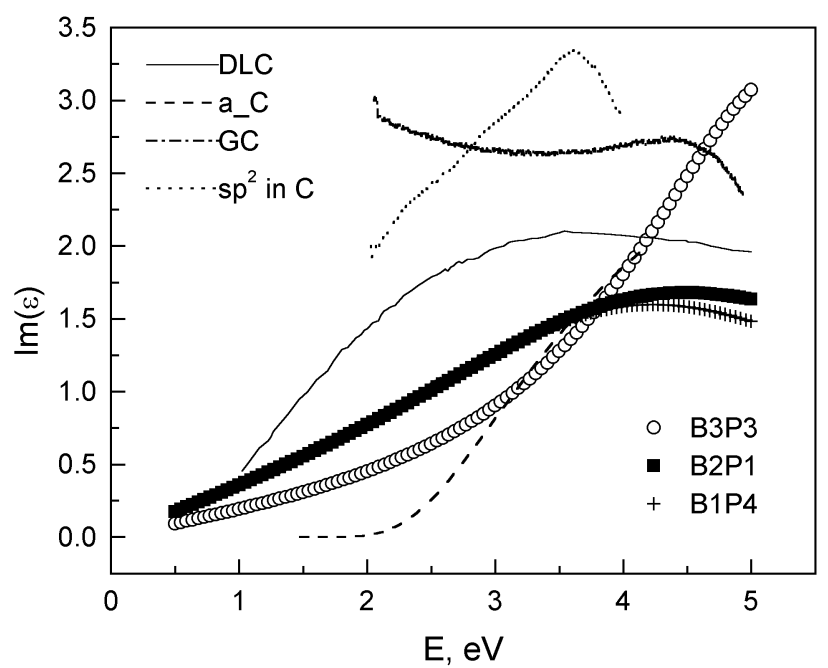

(b)

Fig. 6. Dielectric function spectra of DLC films for investigated a-C:H/Si samples (points) and reference data: DLC is for diamond like amorphous carbon "with $76 \%$ of diamond like component" [33], a-C is the data for "amorphous carbon" [28], GC and $s p^{2}$ in $\mathrm{C}$ are the spectra obtained for glassy carbon and the component of $s p^{2}$-bonded $\mathrm{C}$ atoms in diamond film [15].

The absorption spectra of thick DLC films was also described by the modified Tauc-Lorentz model for amorphous materials [34] which is based on the Tauc joint density of states and the Lorentz oscillator:

$$
\operatorname{Im}(\varepsilon(E))=\frac{A E_{0} C\left(E-E_{\mathrm{g}}\right)^{2}}{\left(E^{2}-E_{0}^{2}\right)^{2}+(C E)^{2}} \cdot \frac{1}{E},
$$

where $E_{0}$ is the energy of a single Lorentz line, $E_{\mathrm{g}}$ is the threshold energy for interband transitions, both considered as fitting parameters along with the amplitudes $A$ and $C$. The $E_{0}$ value for thick samples B1P4, B2P1, and $\mathrm{B} 3 \mathrm{P} 3$ is equal to $4.95,5.23$, and $5.55 \mathrm{eV}$, respectively, indicating an increased contribution of the energy of $\sigma \rightarrow \sigma^{*}$ transitions in $s p^{3}$ sites in these series. It should be noted that the contribution of thin DTC films to the optical response is too weak for analysis of the data in the framework of any complex model. However, as noted above, the dielectric function of thin DLC films is close to that for amorphous carbon. The corresponding $E_{0}$ value $(4.13 \mathrm{eV})$, which follows from the Tauc-Lorentz model (3) for a-C [28], agrees well with those for thick DLC films.

Some difference in the optical constants determined from reflectance and ellipsometry should also be noted. This observation indicates that the DLC samples studied were nonhomogeneous along the surface normal. This observation is in agreement with uniaxial optical anisotropy noticed previously [8].

Summarizing, the provided studies of a-C:H/Si samples have shown a significant difference in the optical properties of DLC films. Some particular features of optical properties were correlated to the technological peculiarities and structural characteristics of a-C:H films grown from $\mathrm{C}_{2} \mathrm{H}_{2}+\mathrm{H}_{2}$ plasma.

\section{Acknowledgements}

The authors are thankful to Dr. I. Šimkiene for discussions and A. Kalinichenko for the assistance in the measurements on AFM. This work was supported by Lithuanian State Science and Education Foundation.

\section{References}

[1] J. Robertson, Amorphous carbon, Adv. Phys. 35, 317374 (1986).

[2] D.L. Pappas, K.L. Saenger, J. Bruley, W. Krakow, J.J. Cuomo, T. Gu, and R.W. Collins, Pulsed laser deposition of diamond-like carbon films, J. Appl. Phys. 71, 5675-5684 (1992).

[3] J.J. Hauser, Electrical, structural and optical properties of amorpous carbon, J. Non-Cryst. Solids 23, 21-41 (1977).

[4] M. Yoshikawa, G. Katagiri, H. Ishida, A. Ishitani, and T. Akamatsu, Raman spectra of diamond-like amorphous carbon films, J. Appl. Phys. 64, 6464-6468 (1988).

[5] S. Gupta, B.R. Weiner, and G. Morell, Ex situ spectroscopic ellipsometry and Raman spectroscopy investigations of chemical vapor deposited sulfur incorporated nanocrystalline carbon thin films, J. Appl. Phys. 92, 5457-5462 (2002).

[6] S. Xu, B.K. Tay, H.S. Tan, L. Zhong, Y.Q. Tu, S.R.P. Silva, and W.I. Milne, Properties of carbon ion deposited tetrahedral amorphous carbon films as a function of ion energy, J. Appl. Phys. 79, 7234-7240 (1996). 
[7] M.J. Paterson, Energy dependent structure changes in ion beam deposited a-C:H, Diamond Relat. Mater. 5, 1407-1413 (1996).

[8] T. Schwarz-Sellinger, A. von Keudell, and W. Jacob, Plasma chemical vapor deposition of hydrocarbon films: The influence of hydrocarbon source gas on the film properties, J. Appl. Phys. 86, 3988-3996 (1999).

[9] J. Hong, A. Goulett, and G. Turban, Ellipsometry and Raman study on hydrogenated amorphous carbon (a-C:H) films deposited in a dual ECR-r.f. plasma, Thin Solid Films 352, 41-48 (1999).

[10] B. Hong, M. Wakagi, R.W. Collins, I. An, N.C. Engdahl, W. Drawl, and R. Messier, Real-time spectroscopic ellipsometry studies of diamond film growth by microwave plasma-enhanced chemical vapor deposition, Diamond Relat. Mater. 3, 431-437 (1994).

[11] H. Lee, I.-Y. Kim, S.-S. Han, B.-S. Bae, M.K. Choi, and I.-S. Yang, Spectroscopic ellipsometry and Raman study of fluorinated nanocrystalline carbon thin films, J. Appl. Phys. 90, 813-818 (2001).

[12] L. Fayette, B. Marcus, M. Mermoux, L. Abello, and G. Lucazeau, In-situ Raman investigation of diamond films during growth and etching processes, Diamond Relat. Mater. 3, 438-442 (1994).

[13] X. Zhang, W.H. Weber, W.C. Vassell, T.J. Potter, and M.A. Tamor, Optical study of silicon-containing amorphous hydrogenated carbon, J. Appl. Phys. 83, 28202825 (1998).

[14] Y. Cong, R.W. Collins, G.F. Epps, and H. Winduschmann, Spectroellipsometry characterization of optical quality vapor-deposited diamond thin films, Appl. Phys. Lett. 58, 819-821 (1991).

[15] B. Hong, J. Lee, R.W. Collins, Y. Kuang, W. Drawl, R. Messier, T.T. Tsong, and Y.E. Strausser, Effects of processing conditions on the growth of nanocrystalline diamond thin films: Real time spectroscopic ellipsometry studies, Diamond Relat. Mater. 6, 55-80 (1997).

[16] C.E. Nebel, Electronic properties of CVD diamond, Semicond. Sci. Technol. 18, S1-S11 (2003).

[17] J. Robertson, Electronic and atomic structure of diamond-like carbon, Semicond. Sci. Technol. 18, S12-S19 (2003).

[18] J. Robertson, Recombination and photoluminescence mechanism in hydrogenated amorphous carbon, Phys. Rev. B 53, 16302-16305 (1996).

[19] P.J. Fallon, V.S. Veerasamy, C.A. Davis, J. Robertson, G.A.J. Amaratunga, W.I. Milne, and J. Koskinen, Properties of filtered-ion-beam-deposited diamondlike carbon as a function of ion energy, Phys. Rev. B 48, 4777-4782 (1993).
[20] R. Robertson, J. Robertson, and G.A.J. Amaratunga, Photoluminescence behavior of hydrogenated amorphous carbon, J. Appl. Phys. 80, 2998-3003 (1996).

[21] A.C. Ferrari and J. Robertson, Interpretation of Raman spectra of disordered and amorphous carbon, Phys. Rev. B 61, 14095-14107 (2000).

[22] D. Tribandis, A. Grigonis, V. Kopustinskas, and S. Gabrenas, Properties of diamond-type carbon coatings obtained from mixture of $\mathrm{C}_{2} \mathrm{H}_{2} / \mathrm{H}_{2}$, in: Taikomoji Fizika (Applied Physics), Proc. Conf. "Lithuanian Science and Industry” (Technologija, Kaunas, 2002) pp. 39-40.

[23] M. Silinskas and A. Grigonis, Low energy postgrowth irradiation of amorphous hydrogenated carbon (a-C:H) films, Diamond Relat. Mater. 11, 1026-1030 (2002).

[24] A. Galickas, Regression analysis in experimental technique, Lithuanian J. Phys. 39, 149-153 (1999).

[25] G.-J. Babonas, L. Leonyuk, V. Maltsev, R. Szymczak, A. Reza, M. Baran, and L. Dapkus, Physical properties of $\left(\mathrm{M}_{2} \mathrm{Cu}_{2} \mathrm{O}_{3}\right)_{m}\left(\mathrm{CuO}_{2}\right)_{n}(\mathrm{M}=\mathrm{Ca}, \mathrm{Sr}, \mathrm{Bi})$ single crystals with Bi-2212 phase on their surface, Acta Phys. Pol. A 100, 553-563 (2001).

[26] A. Matulis and J. Babonas, Program "Reflect", in: Proc. SPI 14th Conf. (Semiconductor Physics Institute, Vilnius, 2002).

[27] M. Born and E. Wolf, Principles of Optics (Pergamon Press, Oxford, 1968).

[28] http: / / www. sopra-sa.com/indices.htm

[29] S. Xu, L.K. Cheah, and B.K. Tay, Spectroscopic ellipsometry studies of tetrahedral amorphous carbon prepared by filtered cathodic vacuum arc technique, Thin Solid Films 312, 160-169 (1998).

[30] A. von Keudell and W. Jacob, Interaction of hydrogen plasmas with hydrocarbon films, investigated by infrared spectroscopy using an optical cavity substrate, J. Vac. Sci. Technol. A 15, 402-407 (1997).

[31] U. Rossow, Optical characterization of porous materials, Phys. Status Solidi A 184, 51-78 (2001).

[32] A.R. Forouhi and I. Bloomer, Optical dispersion relations for amorphous semiconductors and amorphous dielectrics, Phys. Rev. B 34, 7018-7026 (1986).

[33] N. Savvides, Optical constants and associated functions of metastable diamond-like amorphous carbon films in the energy range $0.5-7.3 \mathrm{eV}$, J. Appl. Phys. 59, 4133-4145 (1986).

[34] G.E. Jellison and F.A. Modine, Parametrization of the optical functions of amorphous materials in the interband region, Appl. Phys. Lett 69, 371-373 (1996). 


\title{
AMORFINIŲ HIDROGENIZUOTU ANGLIES SLUOKSNIŲ OPTINĖS SAVYBĖS
}

\author{
G.J. Babonas ${ }^{\text {a,b }}$, A. Rèza ${ }^{\text {a,c }}$, A. Grigonis ${ }^{d}$, D. Tribandis ${ }^{d}$, R. Tamaševičius ${ }^{a}$, A. Kindurys ${ }^{\text {a }}$ \\ a Puslaidininkiu fizikos institutas, Vilnius, Lietuva \\ ${ }^{\mathrm{b}}$ Vilniaus Gedimino technikos universitetas, Vilnius, Lietuva \\ ${ }^{\mathrm{c}}$ Vilniaus pedagoginis universitetas, Vilnius, Lietuva \\ ${ }^{\mathrm{d}}$ Kauno technologijos universitetas, Kaunas, Lietuva
}

\section{Santrauka}

Tirti amorfiniai deimanto tipo hidrogenizuoti anglies sluoksniai, užauginti ant $\mathrm{Si}$ padèklų iš $\mathrm{C}_{2} \mathrm{H}_{2}+\mathrm{H}_{2}$ plazmos. Iš šios kompleksinès sistemos optinio atsako UV-VIS-IR spektro ruože $(1-5 \mathrm{eV})$, tiriamo elipsometriniu ir atspindžio metodais, ìvertintos
a-C:H sluoksniu optinès konstantos. Nagrinejjami a-C:H sluoksniai apibūdinti efektyvaus sluoksnio modeliu, tačiau optinis atsakas analizuotas daugiasluoksniu modeliu. Optinių a-C:H sluoksnių, išaugintų iš $\mathrm{C}_{2} \mathrm{H}_{2}+\mathrm{H}_{2}$ plazmos, savybių būdingi bruožai buvo susieti su technologijos ir sandaros ypatumais. 